\title{
Performance of a Score-Stove with a Kerosene Burner and the Effect of Pressurization of the Working Fluid
}

\author{
Md Ehsan', Manabendra Sarker'1, Rifath Mahmud1, Paul H. Riley² \\ ${ }^{1}$ Department of Mechanical Engineering, Bangladesh University of Engineering and Technology (BUET), \\ Dhaka, Bangladesh \\ ${ }^{2}$ Department of Electrical Engineering, University of Nottingham, Nottingham, UK \\ Email: ehsan@me.buet.ac.bd
}

Received January 2015

\begin{abstract}
Score-Stove ${ }^{\mathrm{TM}}$ a clean-burning cooking stove that also generates electricity was tested using a pressurized kerosene burner. The Score-Stove works on the principle of thermo-acoustics to generate small-scale electricity. The device having hot-end, cold-end and regenerator acts in a way similar to a stirling cycle generating acoustic power, which is then converted to electricity using a linear actuator. It can supply small power for applications such as LED lighting, mobile phone charging and radios particularly in rural areas without grid electricity as well as improving household air pollution. After assessing the needs of the rural communities through a survey, tea-stalls and small restaurants owners were identified as clients with the most potential of using the stove in Bangladesh. Bangladesh University of Engineering and Technology ((BUET) modified a ScoreStove to use both wood and a pressurized kerosene burner of a design that is widely used for cooking in rural areas of Bangladesh. The design was adapted to meet performance needs such as: heating rate, cooking efficiency, energy distribution, electric power generation, exhaust emissions and time taken to boil water using standardized water boiling tests. Performance was also compared with conventional (non-electrically generating) stoves that use a pressurized kerosene burner. The Score-Stove performance was then evaluated while increasing the pressure of the sealed working fluid (air in this case) from atmospheric to about 1.4 bar. The pressurization was found to almost double the power generation. An arrangement for utilizing cooling water waste heat was also devised in order to improve the thermal performance of the stove by $18 \%$. Technical deficiencies are documented and recommendations for improvements and future research in order to obtain wider end-user acceptance are made.
\end{abstract}

\section{Keywords}

Score-Stove, Small-Scale Power, Thermo-Acoustics, Clean Cooking Stove, Kerosene Burner, Pressurization 


\section{Introduction}

Developing a low pollution, fuel efficient and affordable cooking stove can change the life of billions of people around the world, particularly in Sub-Saharan Africa, the Indian subcontinent and South America where people cook on open fire stoves and are largely deprived of grid electricity as well. Inefficient burning causes thousands of tons of carbon emission as well as serious health hazards to the users, which causes almost four million people to die prematurely each year due to household air pollution (HAP) [1]. The Lancet [2] states that household air pollution is the leading risk factor for premature deaths in south Asia.

Despite the high death rates, the problem continues to be intractable for a variety of reasons [3]. The World Bank [4] states "...In short, many approaches to introducing improved stoves have been tried, with some successes and many failures...”. There is a growing body of opinion that more radical approaches are needed [5]. Riley [6] argues that the addition of electrical generation to cooking stoves increases the affordability and hence social acceptance of clean cooking. Studies in Malawi [7] using thermo-electric technology have made some progress, although the power produced is low, about three Watts of electricity. Another thermo-electric stove that is commercially available for use in developed countries and has had trials in Laos is the Biolite [8] that produces about 2 to 3 Watts. It only takes small pieces of wood and so is thought unsuitable for areas where cut wood is long [9]. Recent developments in thermo-acoustic technology have shown potential to provide solutions to the problems set out above [10]-[12]. This paper describes the use in Bangladesh of the Score-Stove ${ }^{\mathrm{TM}}$ that incorporates the thermoacoustic principle to generate electricity whilst cooking by converting excess thermal energy into electrical energy before releasing waste energy to the atmosphere [13]. With the use of a chimney and proper combustion of air-fuel, the stove can provide a non-smoky and healthier environment inside the kitchen. After assessing the needs of the rural communities through a survey, tea-stalls and small restaurants owners were identified as people with the most potential of using the stove in Bangladesh. Later the pressure of the sealed working fluid was increased to see the effect on the power generated.

\section{Background and Working Principle}

Byron Higgins (1777) first documented the themoacoustic phenomenon [14]. A century later Lord Rayleigh explained the phenomenon qualitatively [15], in the 1960s'. From then until the 1990's others progressed understanding [16] [17] until progress became much more rapid through the theoretical work of Swift [18] at Los Alamos laboratories [19] and the practical realizations of deBlok from Aster [20]. Figure 1 below shows the basic components of a dual full wavelength, looped tube travelling wave engine as used in the Score-Stove ${ }^{\mathrm{TM}}$.

In a thermoacoustic engine (TAE), heat is supplied from a source to a gas (air in Score-Stove) via the hot heat exchanger (HHX), heat is removed via the ambient heat exchanger (AHX) and the gas undergoes repetitive

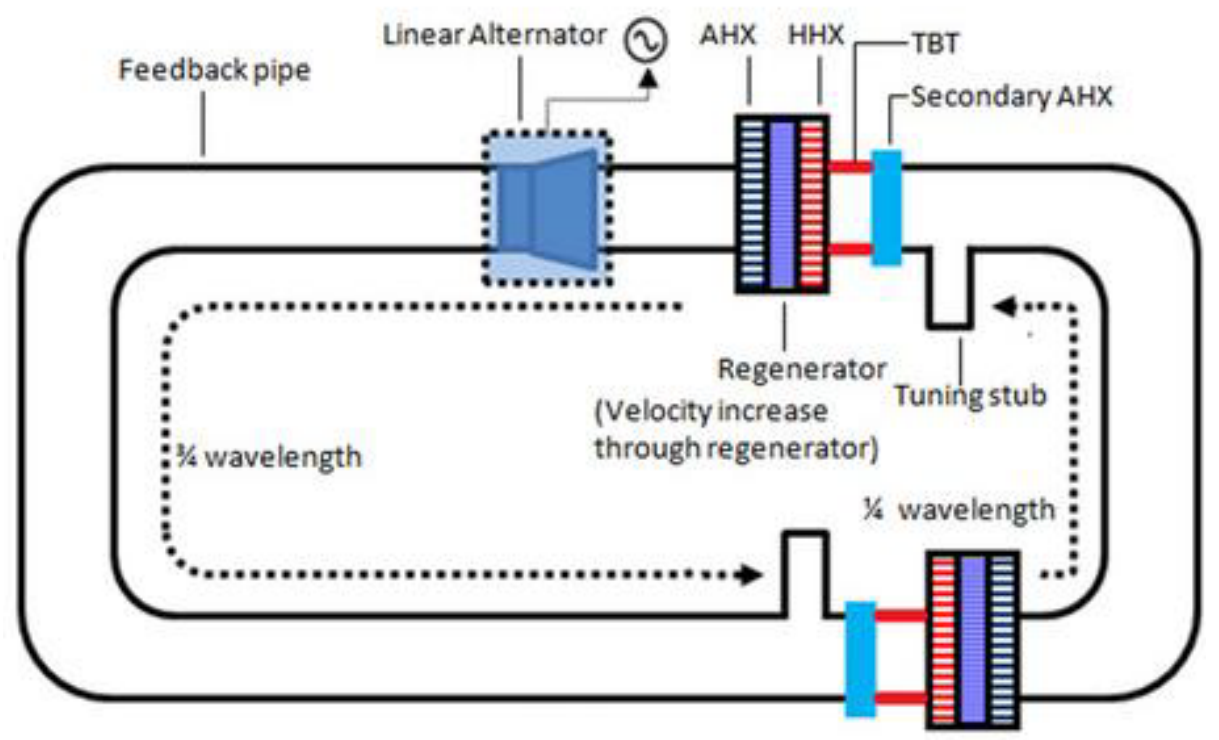

Figure 1. Functional diagram of Score-Stove. 
thermal expansion and rarefaction to produce acoustic energy. Between the HHX and AHX a temperature gradient is formed in a porous material called the regenerator that sustains a resonant acoustic wave. A linear alternator (a loudspeaker working in reverse for the field trials) within the closed loop converts the acoustic wave into electricity. Previous works reported change in onset temperature [21] and increase of power generated when pressure of the sealed working fluid was increased [22]. However, this requires stronger materials and better joint seals, which tend to increase the cost of the stove.

\section{Modification of the Score-Stove}

The basic stove design described in reference [13] [23] was modified in two ways. Firstly, the TAE working gas was pressurised and secondly, the waste heat from the TAE was used to pre-heat water for cooking as described in the following paragraphs. The increase in pressure was modest and within the limits of the low cost materials.

\section{Score-Stove Performance Analysis}

Stove performance was tested during typical water boiling tests (WBT) and the heat input rate was calculated from the gravimetric measurement of the fuel consumption rate and the lower heating value. Temperatures of the flue gas, TAE, HHX and AHX were recorded using K-type thermocouples and a National Instruments compact data acquisition system. Mass flow rate and temperatures of the cooling water and the exhaust leaving the chimney were recorded to estimate the heat losses. The electric power voltage and current produced from the linear actuator was measured using a watt-meter with either LED lights or a variable resistance as a load in order to check the sensitivity at different loads. The major parameters recorded during the laboratory water boiling test are given in Table 1. For the WBT, two identical water pots each filled with 2 litres of water were placed on the stove. Resonance started after about 11 minutes of heating at about $64 \mathrm{~Hz}$ and the lights came on within 12 minutes. The first pot reached a temperature of $80^{\circ} \mathrm{C}$ after about 39 minutes, while the water in the second pot reached $64^{\circ} \mathrm{C}$. It took 15 minutes more to get another pot of hot water at $80^{\circ} \mathrm{C}$ if the preheated water of the second pot was used to replace the water in the first pot. More details of the WBT results are given in [13]. Later increasing working fluid pressure and recovery of cooling water heat were studied to improve stove performance.

Being a heat engine the Score-Stove TAE is limited by the second law of thermodynamics and Carnot's law so TAE efficiency is a function of the temperature difference between HHX and AHX. Figure 2 shows heat flows of the stove under test and Table 2 shows the component shares of energy distribution during a WBT test. It was noted that the time requirement for boiling in the Score-Stove was longer (in about 39 min) compared to boiling the same pot of water directly using the conventional pressurised kerosene burner (typically in about 10 min). This is because in the conventional stove, the flame directly comes in contact to the pot and the temperature difference across the water in the pot and the flames are higher which facilitated a greater rate of heat transfer and faster heating. In the case of Score-Stove, the flame from the burner first passes by the TAE and then reaches the boiling pots in sequence, which reduces flame temperature thus reducing the temperature gradient and the rate of heat transfer. In the unit tested, waste heat from the AHX is vented to atmosphere and so is not doing useful work.

Table 1. WBT results of the Score-Stove.

\begin{tabular}{|c|c|}
\hline Amount of water & $2 \mathrm{~kg}$ water in each of two pots \\
\hline Temperature & From $26^{\circ} \mathrm{C}$ room temperature to $80^{\circ} \mathrm{C}$, took $39 \mathrm{~min}$ for pot- 1 \\
\hline Fuel & Kerosene \\
\hline Resonance initiation (onset) & 11 min 17 seconds after start-up, Frequency: $64 \mathrm{~Hz}$ \\
\hline Power output & About 3.5 watts (2 LED lamps) \\
\hline Maximum current & 0.7 Amp at 5 volts \\
\hline Fuel consumed & $0.36 \mathrm{Lit} / \mathrm{hr}$ \\
\hline TAE hot-end temp & $700^{\circ} \mathrm{C}$ \\
\hline Exhaust temp & $175^{\circ} \mathrm{C}$ \\
\hline Exhaust condition & Clear exhaust, almost invisible \\
\hline
\end{tabular}


Table 2. Energy distribution during a WBT test.

(a)

\begin{tabular}{cc}
\hline INPUT ENERGY COMPONENT & Value \\
\hline Fuel consumption at $26^{\circ} \mathrm{C}$ room & $0.194 \mathrm{~kg}$ \\
Assumed burning efficiency & $95 \%$ \\
Input heating rate & $3325 \mathrm{~W}$ \\
Total energy during WBT (100\%) & $7780 \mathrm{~kJ}$ \\
\hline
\end{tabular}

(b)

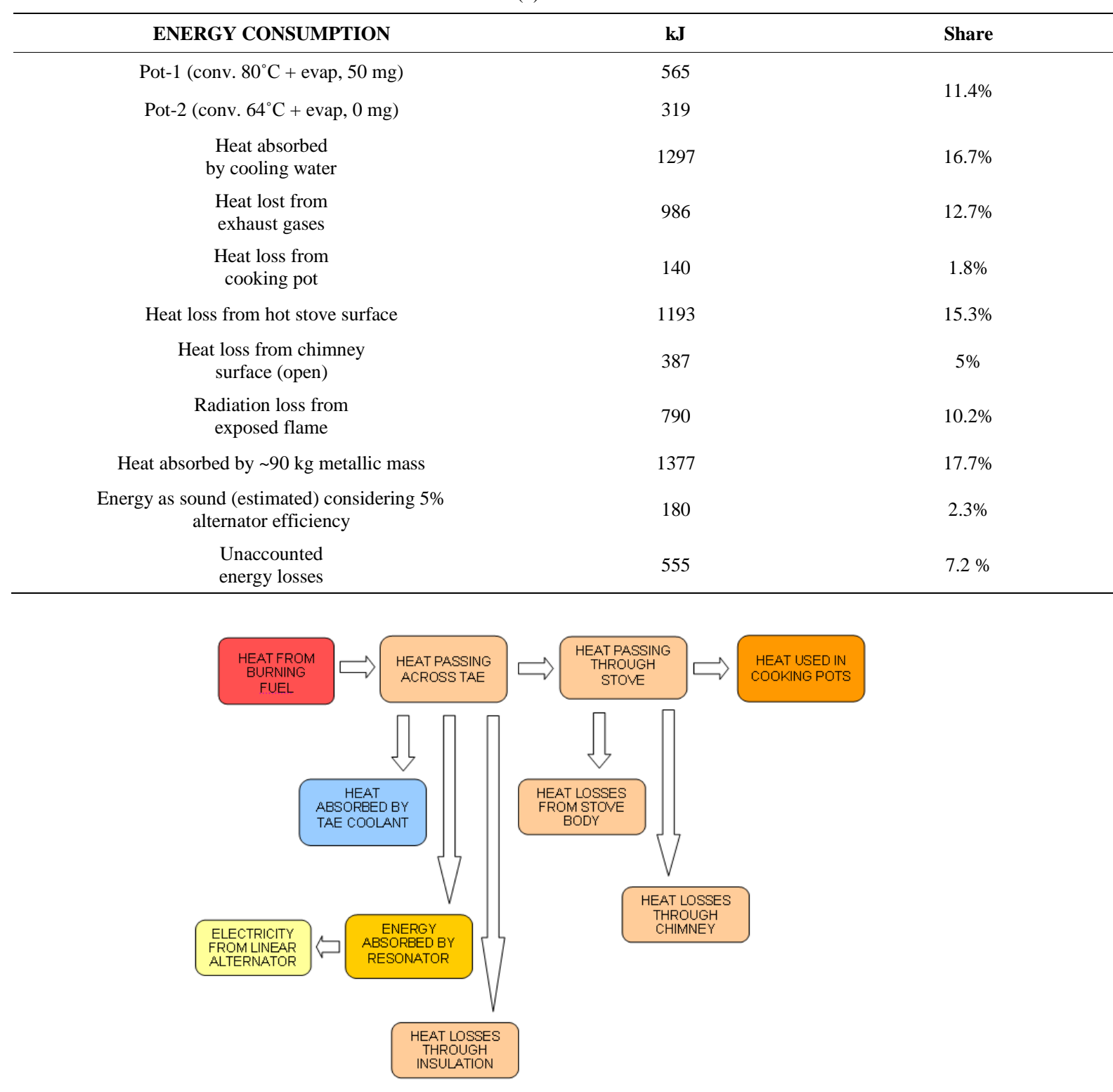

Figure 2. Energy balance of Score-Stove.

Higher flame temperatures would have been achieved by restricting the airflow and keeping combustion closer to stoichiometric conditions (less excess air). However, laboratory experiments showed that this higher flame temperature caused gradual overheating of the fuel tank as more heat started to be conducted through the 
metallic fuel line up to the burner. This increased the vaporisation of kerosene fuel, which increased the fire risk significantly and so was considered unsafe for field trials. The problem also could be solved by reorienting the fuel tank and connecting it with a non-metallic high-temperature withstanding pressure hose. However this would compromise the simplicity of the present design and convenience of directly plugging in the very popular pressurised kerosene stove. So in practice the common pressurised kerosene burner design at present has limitation regarding increasing of flame temperature [13] hence the heat transfer rate decreases causing longer time requirement of the Score-Stove for performing the WBT.

\section{Score-Stove with Pressurization}

\subsection{Theoretical Considerations}

The characteristic acoustic impedance of a pipe $Z_{0}$, is:

$$
Z_{0}=\frac{\rho c}{A}
$$

where $c$ is the speed of sound in the pipe, $A$ is the pipe area and the density of the gas $\rho$ varies with mean pressure so that the density of the working gas $\rho_{w}$ is:

$$
\rho_{w}=\frac{\rho_{0} P_{m}}{P_{0}}
$$

where $P_{m}$ is the mean pressure in the pipe and $P_{0}$ is the pressure at the defined density $\rho_{0}$. Giving:

$$
Z_{0}=\frac{\rho_{0} P_{m} c}{P_{0}}
$$

Acoustic power in a travelling wave travelling is:

$$
W_{a}=p v A
$$

where $p$ is the dynamic pressure variation, $v$ is the particle velocity and $A$ is the pipe area.

The drive ratio $D_{r}$ has a value of around $5 \%$ to $10 \%$ in practical thermo-acoustic engines, defined as:

$$
D_{r}=\frac{p}{P_{m}}
$$

Substituting $p$ from 5.3 into 5.2 gives:

$$
W_{a}=D_{r} P_{m} A v
$$

Pressure is related to velocity by the pipe impedance:

$$
p=Z_{0} v
$$

Therefore

$$
W_{a}=\frac{D_{r}^{2} P_{m}^{2} A}{Z_{0}}
$$

And

$$
W_{a}=v^{2} \frac{\rho_{0} P_{m} c A}{P_{0}}
$$

Substituting gives:

$$
v=\frac{D_{r} P_{0}}{\rho_{0} c}
$$

Equation (5.6) shows that for a fixed pipe diameter and drive ratio, acoustic power is proportional to the square of the mean pressure. Furthermore, Equation (5.8) shows that for a fixed drive ratio and pipe area, velocity is constant and independent of $P_{m}$. 
There are two main sources of loss in a TAE: pipe losses that are mainly a function of particle velocity, and losses in the regenerator that are a function of velocity, gas density (i.e. pressure) and gas viscosity. As the regenerator has a larger area than the pipe, velocity through it is lower than pipe velocity. Increasing $P_{m}$ by small amounts increases pipe acoustic power, but losses stay the same, therefore we predict efficiency to improve. For larger increases in $P_{m}$, losses in the regenerator increase and so efficiency will level off.

\subsection{Experimental Results}

The pressurizing apparatus consisted of a small reciprocating compressor fitted with a pressurized air tank. Figure 3 shows the set-up used for pressurizing the stove using compressed air from a reciprocating compressor. The sealing at this stage was only capable of safely withstanding up to $1.5 \mathrm{bar}$ of air pressure in the resonance tube. The initial surge of air from the compressor caused a rapid rise of air pressure in the resonance tube and it was difficult to attain and maintain a particular pressure level. Therefore, the tank was filled with compressed air and the compressor turned off. A precision flow control valve was fitted between the tank and the resonance tube. The stove was heated up and pressure of air in the system was raised to about 1.5 bars then by gradually releasing air from the tank, readings were recorded at resonance from 1.35 bar to about atmospheric level.

However, the stove performance of the pressurized kerosene burner and the linear alternator showed some variations in repeating runs, which is showed as a band as in Figure 4(a). Variations in-heating rate of the typical kerosene burner, condensation of some water vapours in the resonance tube, performance of linear alternator, are jointly responsible for such differences. The general trend showed a non-linear $\left(2^{\text {nd }} / 3^{\text {rd }}\right.$ order $)$ increase of electric power developed with the increase of air pressure of the resonance tube. With air pressure from atmospheric to about 1.35 bar the average rise of power output from the linear alternator almost doubled as shown in Figure 4(b) and is in line with the theoretical predictions. However, higher air pressure caused larger forces acting on the tube joints and at the present condition of sealing, the pressure could be sustained only for about 20 minutes.

\section{Score-Stove the Cha-Wala Version}

The regular version of the Score-Stove uses a supply of cooling water around the cold-end of the regenerator mesh and the auxiliary heat exchanger or a radiator heat exchanger to keep the temperature of the cold-end close to room temperature. For application like small tea stalls a water reservoir can be used for this purpose, which could also be a source of preheated water for boiling using waste heat. This originated the idea of the "Cha-Wala" (it means the vendor who sells tea) version of the Score-Stove, where the cold end of the TAE was submerged in an additional water tank eliminating the use of radiator or line supply of cooling water. During the operation of

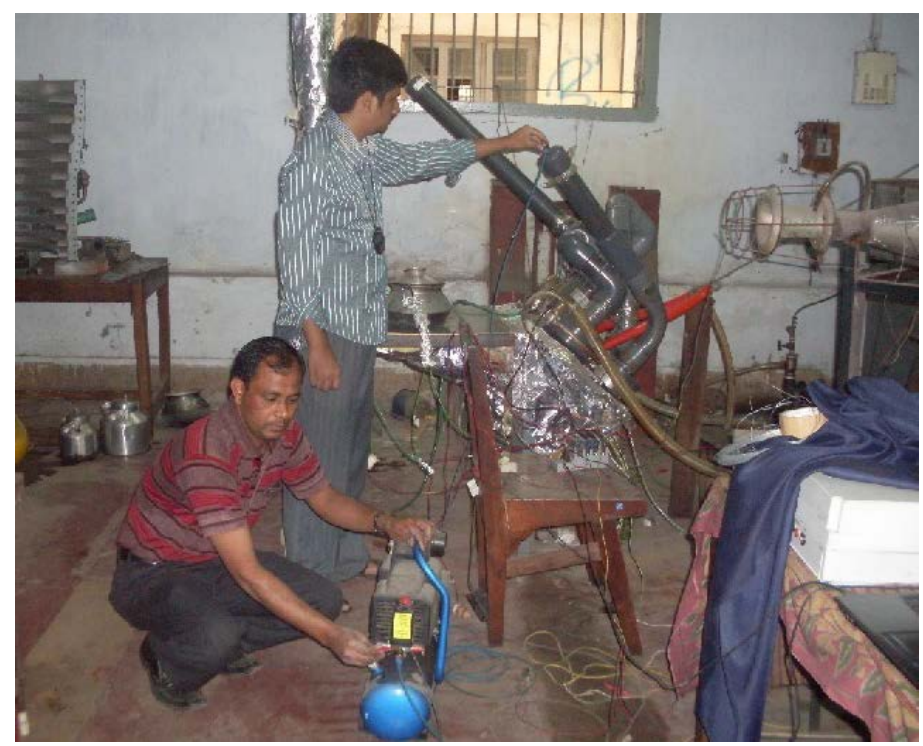

Figure 3. Pressurizing the system with compressed air. 


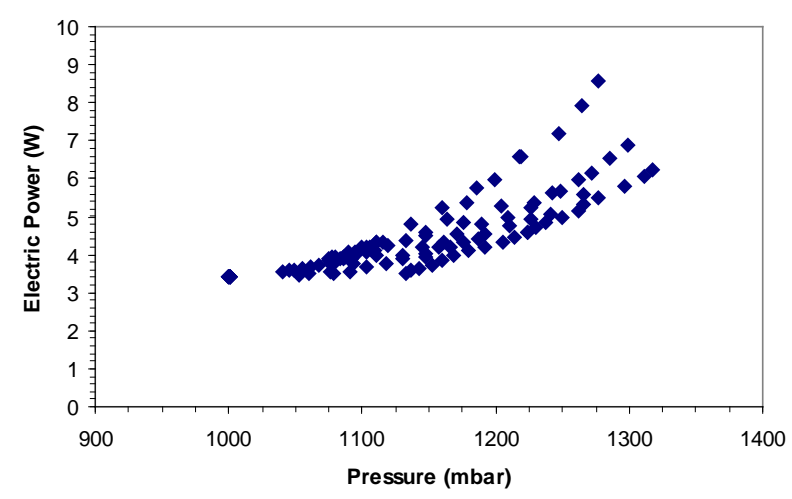

(a)

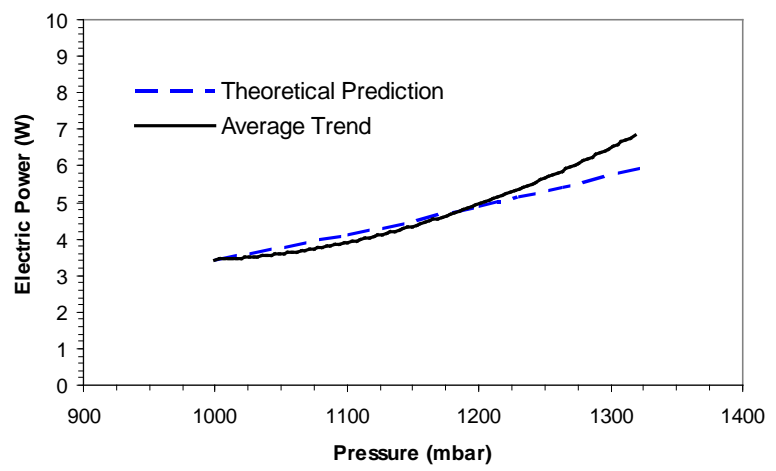

(b)

Figure 4. (a) Variation of power with air pressure; (b) Trend of increase in power generated.

the stove the water in this tank gets gradually heated up, which can be tapped as pre-heated feed in the boiling water container. This reduces the time required for boiling as well as improving the thermal efficiency of the system. In this process, some of the waste heat is recovered, reducing the overall heat losses.

The "Cha-Wala" in Figure 5 Stove performance was also evaluated using typical WBT. Parameters were recorded as the water temperature in the cooking pot reached $80^{\circ} \mathrm{C}$ and $100^{\circ} \mathrm{C}$ from room temperature of $22^{\circ} \mathrm{C}$.

The first of the two pots reached a temperature of $80^{\circ} \mathrm{C}$ after about 32 minutes and $100^{\circ} \mathrm{C}$ after about 44 minutes, while the water in the second pot reached $52^{\circ} \mathrm{C}$ and $64^{\circ} \mathrm{C}$ at the respective times. It took 14 minutes more to get another pot of hot water at $100^{\circ} \mathrm{C}$ if the preheated water of the second pot was used to replace the water in the first pot. The water in upper portion of the water tank was warmer than the water in the lower portion because of the nature of convection. This preheated water gained a temperature of about $33^{\circ} \mathrm{C}$ (in upper portion) and an average temperature of about $28^{\circ} \mathrm{C}$ at the time of the boiling of water in the first pot. This preheated water was then used in the second pot to make the cooking even faster. The Cha-Wala version could heat the first pot 7 minutes (18\%) earlier compared to the standard version described before, reflecting the utilization of wasted heat.

\section{Conclusions}

The Score-Stove provides a unique solution using thermoacoustic technology regarding the use of waste heat during cooking and the potential to produce small-scale electricity, especially for the people who do not have the access to mains electricity.

The current design is capable of using multiple fuels and acceptable for limited field trials to obtain end-user feedback. However, its performance is lower than that required to compete with conventional pressurized kerosene cooker. Further adaptations are required to improve performance and ensure safety under typical end use.

Two features for improving the performance investigated are: increase of pressure of the working fluid and reusing the waste heat. The increase of pressure by 1.4 times almost doubled the power produced and fits well 

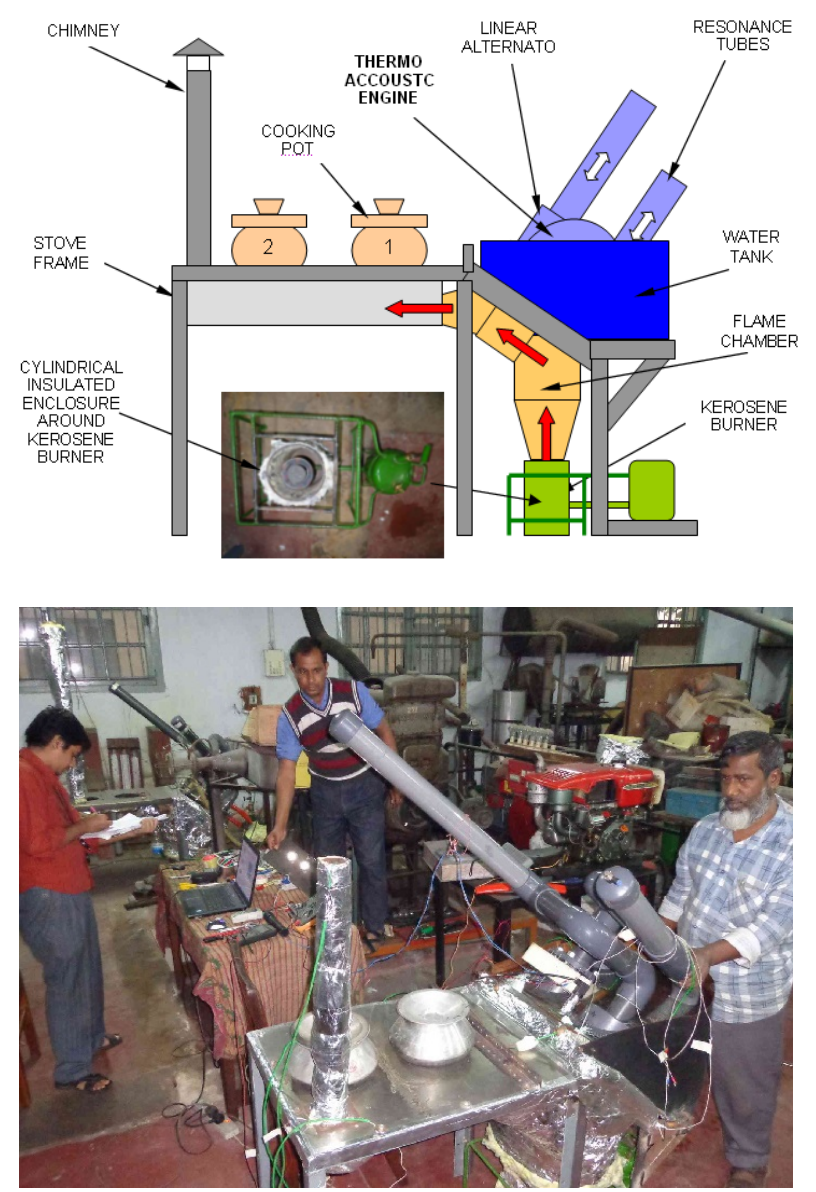

Figure 5. Cha-Wala version of the stove.

with the theoretical predictions. The recovery of heat lost in cooling the cold-end is incorporated in the ChaWala version of the stove, which reduces the cooking time by $18 \%$. These are rich areas for further research and development and provided the changes give sufficient improvement, the Score-Stove has the potential to make an impact on the target users.

\section{Acknowledgements}

The authors would like to thank University of Nottingham UK and Bangladesh University of Engineering and Technology (BUET) for using their facilities and EPSRC for financial support of the research project.

\section{References}

[1] Malik, A.S., Boyko, O., Atkar, N. and Young, W.F. (2001) A Comparative Study of MR Imaging Profile of Titanium Pedicle Screws. Acta Radiologica, 42, 291-293. http://dx.doi.org/10.1080/028418501127346846

[2] Bartlett, S. (2012) New Study Estimates 4 Million Deaths from Household Cooking Smoke Each Year. Press Release December 13, Global Alliance for Clean Cookstoves.

http://www.cleancookstoves.org/media-and-events/press/new-study-estimates-4-million-from-household-cooking-smo ke-each-year.html

[3] Lim, S.S., et al. (2012) A Comparative Risk Assessment of Burden of Disease and Injury Attributable to 67 Risk Factors and Risk Factor Clusters in 21 Regions, 1990-2010: A Systematic Analysis for the Global Burden of Disease Study 2010. The Lancet, 380, 2224-2260. http://dx.doi.org/10.1016/S0140-6736(12)61766-8

[4] Household Cookstoves Environment, Health, and Climate Change. http://climatechange.worldbank.org/sites/default/files/documents/Household\%Cookstoves-web.pdf

[5] SCORE website. http://www.score.uk.com/default.aspx 
[6] Riley, P.H. (2014) Affordability for Sustainable Energy Development Products. Journal of Applied Energy, 132, 308316. http://dx.doi.org/10.1016/j.apenergy.2014.06.050

[7] O’Shaughnessy, S.M., Deasy, M.J., Kinsella, C.E., Doyle, J.V. and Robinson, AJ. (2013) Small Scale Electricity Generation from a Portable Biomass Cookstove: Prototype Design and Preliminary Results. Journal of Applied Energy, 102, 374-385. http://dx.doi.org/10.1016/j.apenergy.2012.07.032

[8] http://www.biolitestove.com/news-press/news-events/news/biolite-special-field-report---the-homestoves-introduction-i n-laos.html

[9] Chen, B., Abdalla Abakr, Y., Riley, P.H. and Hann, D. (2012) Development of Thermoacoustic Engine Operating by Waste Heat from Cooking Stove. AIP Conference Proceedings, 1440, 532-540. http://dx.doi.org/10.1063/1.4704259

[10] http://www.aster-thermoacoustics.com/wp-content/uploads/2013/09/Design-and-build-of-a-50W-thermacoustic-genera tor2.pdf

[11] Gardner, D.L. and Swift, G.W. (2003) A Cascade Thermoacoustic Engine. The Journal of the Acoustical Society of America, 114, 1905-1919. http://dx.doi.org/10.1121/1.1612483

[12] Backhaus, S. and Swift, G.W. (2000) A Thermoacoustic-Stirling Heat Engine: Detailed Study. Journal of the Acoustical Society of America, 107, 3148-3166. http://dx.doi.org/10.1121/1.429343

[13] Riley, P.H., Ehsan, Md., Sarkera, M. and Mahmud, R. (2014) Performance of an Electricity-Generating Cooking Stove with Pressurized Kerosene Burner. International Conference on Thermal Engineering, Paper No. 93, Dhaka, 20-22 December 2014.

[14] Higgins, B., Nicholson’s Journal I, 130, 1802.

[15] Rayleigh, J.L. (1878) The Explanation of Certain Acoustical Phenomena. Nature, 18, 319-321. http://dx.doi.org/10.1038/018319a0

[16] Carter, R.L., White, M. and Steele, A.M. (1962) Private Communication of Atomics International Division of North American Aviation, Inc., 24 September 1962.

[17] Swift, G.W. (1988). Thermoacoustic Engines. The Journal of the Acoustical Society of America, 84, 1145-1180. http://dx.doi.org/10.1121/1.396617

[18] http://www.lanl.gov/thermoacoustics/DeltaEC.html

[19] http://www.aster-thermoacoustics.com

[20] Sanchez, T., Dennis, R. and Pullen, K.R. (2013) Cooking and Lighting Habits in Rural Nepal and Uganda. Proceedings of the Institution of Mechanical Engineers, Part A: Journal of Power and Energy 0957650913498872, first published on12 September 2013.

[21] Arafa, N., Ibrahim, A.H., Addas, K. and Ehab, A. (2011) Design Considerations for Thermoacoustic Engines for Low Onset Temperature and Efficient Operation. Forum Acusticum, Denmark.

[22] Swift, G.W. (1992) Analysis and Performance of a Large Thermoacoustic Engine. The Journal of the Acoustical Society of America, 92, 1551. http://dx.doi.org/10.1121/1.403896

[23] Chen, B., Riley, P.H., et al. (2011) Design and Testing of a Wood Burning Electricity Generator by using Dual-Core Thermoacoustic Engine. 2011 World Congress on Engineering and Technology (CET), Shanghai. 